\title{
Del acontecimiento teatral al papel: Rabinal Achí1
}

\section{(From the Theatrical Event to Paper: Rabinal Achi)}

\section{Carlos Paniagua ${ }^{2}$}

Universidad Nacional, Costa Rica

\begin{abstract}
Resumen
Este artículo analiza las implicaciones culturales de la fijación, la traducción y la recuperación textual de Rabinal Achí, mediante géneros, instrumentos y principios de filiación europea. Se estudian los distintos momentos históricos de este proceso cultural y sus actores. A partir del examen del discurso teatral, se plantean algunas consideraciones acerca de la relación entre cultura hegemónica y cultura subalterna.
\end{abstract}

\begin{abstract}
This article analyzes the cultural implications of the placement, translation and textual recovery of Rabinal Achí, with European-oriented genres, instruments and principles. The different historical periods of this cultural process are studied along with their actors. Based on theater discourse, certain reflections are presented concerning the relation between hegemonic culture and subaltern culture.
\end{abstract}

Palabras clave: cultura maya prehispánica, teatro maya, literatura guatemalteca

Keywords: Pre-hispanic Mayan culture, Mayan theater, Guatemalan literature

1 Recibido: 11 de setiembre de 2017; aceptado: 17 de setiembre de 2018.

2 Maestría en Estudios de Cultura Centroamericana. Correo electrónico: cpaniagua_dir@hotmail.com

LETRAS 64 (2018), ISSN 1409-424X; EISSN 2215-4094 


\section{Introducción}

Rabinal Achí es un espectáculo de la cultura maya, que los estudiosos han datado del siglo XIII; esto es, en el periodo posclásico maya que comprende entre 900 y 1524 . Es una representación que incluye danza, música con instrumentos autóctonos, diálogos, vestuarios coloridos y máscaras. Se mantiene viva hasta hoy, gracias a una larga tradición oral.

El argumento representa el enfrentamiento de dos pueblos quiché: Rabinal y Cunén. En la representación se narra cómo Rabinal Achí captura a Quiché Achí por intentar apropiarse de sus tierras, haber capturado a su padre y rey de los rabinales Jobtoj y obligarles a pagar tributo. Quiché Achí, tras haber recibido el ofrecimiento del Rey de los rabinales de ser su vasallo, se niega, por lo que Jobtoj lo condena a muerte.

«A finales del año 2005, el Rabinal Achí fue declarada por la UNESCO una de las 43 nuevas Obras Maestras del Patrimonio Oral e Inmaterial de la Humanidad $»^{3}$. Rabinal Achí se presentó ininterrumpidamente desde su creación hasta 1625, cuando la Colonia, a través de Juan Maldonado de Paz, Juez oficial de la Casa de Contratación de las Indias, denunció el espectáculo por idólatra y se alejaba del dogma católico, con lo que prohibió su representación. A pesar de la prohibición, los indígenas asumieron una postura de resistencia en la que clandestinamente seguían reproduciendo su propia cultura.

Las tradiciones orales resultaban mucho más fáciles de conservar, puesto que el aprendizaje y la recitación de los cantos o los discursos no dejaban rastros comprometedores, a menos que espías al servicio de los religiosos fueran a denunciarles aquellas prácticas. [...] Por la misma época, algunos cantos, que conmemoraban la pasada

3 Patricia Henríquez Puentes, «Teatro maya: Rabinal Achí o Danza del tun», Revista Chilena de Literatura 70 (2007): 79-108 (79). DOI: https://doi.org/10.4067/s0718-22952007000100004. 
grandeza de los príncipes, acompañaban las danzas públicas en las que participaba la nobleza indígena ${ }^{4}$.

En 1855 el abate Brasseur Bourbourg transcribió al quiché y tradujo al francés los diálogos que contienen el espectáculo del $R a$ binal Achí. Estos le fueron dictados por Bartolo Ziz, depositario y encargado de preservar la representación. El proceso heteróclito de transvasamiento ${ }^{5}$ es el que se analiza en este ensayo: sacar a luz el contexto y la concepción de subalternidad que enmarca dicho proceso. Se dejará por fuera la representación cultural del pueblo de Rabinal en el texto, pues aportes como el de Patricia Henríquez se han ocupado de ese asunto. Ella tiene como tema recurrente el Rabinal Achí, por lo que en uno de sus estudios: «Teatro maya: Rabinal Achí o Danza del tun» ${ }^{6}$, propone un análisis de la cosmovisión de este pueblo maya, y aborda el ritual de sacrificio, la relación entre la vida y la muerte, la concepción de la guerra, los aspectos jurisdiccionales, políticos y algunos otros detalles de la escenificación. Sobre esto, preparó otro estudio: «Ritos de paso para la puesta en escena del Rabinal Achí o Danza del tun» ${ }^{7}$. Es recomendable consultar ambos estudios para comprender la cultura de este pueblo quiché, desde su cosmovisión y cómo esta afecta la escenificación.

4 Serge Gruzinski, La colonización de lo imaginario. Sociedades indígenas y occidentalización en el México español. Siglos XVI-XVII (México: Fondo de Cultura Económica, 1995) 26.

5 Según León-Portilla, «en muchos lugares del mundo, aunque en diferentes tiempos y de modos distintos, se desarrolló un proceso cultural muy complejo, pero de enorme trascendencia: el paso o transvase de la palabra a alguna forma de escritura» (9). Miguel León-Portilla, El destino de la palabra: de la oralidad y los códices mesoamericanos a la escritura alfabética (México: Fondo de Cultura Económica, 1996).

6 Henríquez Puentes (2007): 79-108.

7 Patricia Henríquez, «Ritos de paso para la puesta en escena del Rabinal Achí o Danza del tun», Revista Chilena de Literatura 70 (2010): 223-235. DOI: https://doi.org/10.4067/ s0718-22952010000100011. 


\section{Del acontecimiento teatral al texto dramático: un proceso heteróclito}

El espectáculo del Rabinal Achí pasó un periodo, desde 1625 hasta 1856, en el que se representaba de manera clandestina por considerarse obra que promovía la idolatría y el paganismo. Este acto de resistencia de los integrantes del pueblo de Rabinal hizo posible conservar los signos gestuales, la plástica escénica ${ }^{8}$ y las partituras de movimientos ${ }^{9}$ que conformaban el texto espectacular ${ }^{10}$, cuya tradición lleva varios siglos y manifiesta los saberes indígenas sobre la ritualidad y la escenificación que dan cuerpo al acontecimiento teatral.

Luis de Tavira, citado por Jorge Dubatti en Introducción a los estudios teatrales, define el teatro como acontecimiento: «El teatro es complejo internamente, porque el acontecimiento teatral se constituye de tres subacontecimientos (por género próximo y diferenciado de otros acontecimientos): el convivio, la poiesis, la expectación» ${ }^{11}$. El convivio se refiere a la presencia de ejecutantes, técnicos y espectadores en un espacio y tiempo determinados, en los que no media la tecnología, es decir, no hay intermediación. Esto conlleva una comunión mediante la acción que se lleva a cabo, pues sucede integrando a todas las personas que habitan ese espacio. El convivio es la «manifestación ancestral de la cultura viviente, diferencia al teatro del cine, la televisión, la

8 Juan Ruesga Navarro, escenógrafo y arquitecto español, define el concepto de plástica escénica como «[...] el conjunto de elementos espaciales, plásticos y visuales que están presentes en el espectáculo teatral: la escenografía, la iluminación, imágenes y proyecciones, el vestuario, el maquillaje y hasta el diseño gráfico» en «Metodología de la Plástica Escénica: La producción artística», Anagnórisis 4 (2011) 88-109 (88).

9 La partitura de movimiento es una secuencia de movimiento que se fija de manera repetitiva; ver: Eugenio Barba, El arte secreto del actor: Diccionario de Antropología Teatral (México: Escenología, 1990).

10 Según Marco De Marinis, son textos espectaculares las «unidades de manifestación teatral que son los espectáculos, tomados en sus aspectos de "procesos" significantes complejos, a la vez verbales y no verbales»; ver Fernando De Toro, Semiótica del teatro: Del texto a la puesta en escena (Buenos Aires: Galerna, 2008) 96.

11 Jorge Dubatti, Introducción a los estudios teatrales (México: Libros de Godot, 2011) 33. 
radio, el Skype y el chateo, porque el teatro exige la presencia viva, real, de cuerpo presente» ${ }^{12}$.

Rabinal Achí, en tanto acontecimiento de convivio, está sujeto a las normas de su cultura; por tanto, es efímero y no se conserva. A pesar de ser una representación ancestral, es irrepetible en tanto comprendamos que los integrantes del acontecimiento (actores y espectadores) cambian, el espacio en el que se representa sufre modificaciones con los años y el tiempo siempre es distinto.

El acontecimiento teatral propicia la convivencia entre actoresintérpretes y espectadores; todos cumplen una función en el hecho escénico. Los primeros son los encargados de la generación de una poiésis; los segundos generan el proceso de expectación. Los actoresintérpretes tienen la función de producir poiésis (acción de crear y poner un objeto a existir) con sus acciones físicas y físico-verbales en relación con los instrumentos musicales, los vestuarios, las máscaras, la utilería, entre otros; es decir, son los productores del acontecimiento poiético.

Los espectadores se encargan del acontecimiento de expectación pues «implica consciencia, al menos relativa o intuitiva, de la naturaleza otra del ente poético» ${ }^{13}$. Existe consciencia ontológica de un hecho escénico paralelo al mundo cotidiano. Este acontecimiento, solo posible por decisión del espectador, permite el acceso a un tiempo mítico/místico que detiene el tiempo real para realizar una conexión con lo absoluto, el teatro como hierofonía o manifestación de lo sagrado, o en el caso del Rabinal Achí, con una historia ancestral:

El Rabinal Achí o Danza del Tun es una obra fundacional del teatro latinoamericano, en tanto actualiza ese momento en la historia del arte escénico de nuestro continente en el que confluían en un mismo tiempo

12 Jorge Dubatti, «Convivio y tecnovivio: el teatro entre infancia y babelismo», Dramateatro Revista Digital (2014).

13 Dubatti (2011) 39; disponible en: <http://www.dramateatro.com/index.php?option=com content\&view=article\&id= 38 :jorgedubatti-1\&catid=13\&Itemid=579\&lang=es $>$. 
y espacio, ritual y teatro, y en el que la puesta en escena se constituía en un acto colectivo de celebración y religación con la divinidad ${ }^{14}$.

Tomando en consideración los factores que integran el acontecimiento teatral y lo señalado por Henríquez, es importante esclarecer algunos fundamentos, sobre la especificidad de la representación del texto espectacular para mostrar todo lo que abarca el espectáculo.

El acontecimiento poiético del espectáculo es complejo, pues incorpora la imaginación de una idea, la generación material de los objetos que permitirán una mayor accesibilidad al espectador a la idea imaginada o mundo poético, y la ejecución por medio de técnicas expresivas que construyan los signos gestuales, musicales y verbales del mundo ficcional. Está compuesto por un texto espectacular, surtido por una serie de elementos que no pueden ser reproducidos mediante la escritura, pueden ser nombrados o explicados, pero nunca manifestarse como tal mediante el texto dramático. Tales elementos son: espacio, tiempo, ritmo escénico, tono, ideologización, proxémica, kinésica, desplazamiento, música, plástica escénica y acciones.

El espacio es determinante en la ejecución: delimita el desplazamiento, el tamaño, soporte y forma de la plástica escénica y las condiciones de enunciación sonora. El tiempo, en el caso del espectáculo de Rabinal Achí, a pesar de ponerse en escena en la misma fecha cada año, no es posible repetirlo por la progresión que tiene. El ritmo escénico está sujeto a variables actanciales, energéticas y psicológicas, que se modifican cada función, pues los actores-intérpretes son personas que poseen una historia de vida y esta determina de una forma u otra la ejecución escénica. El tono de la obra podrá tener una constante más o menos similar entre una representación y otra, ya que existe un depositario que se encarga de re-producir la obra como le fue enseñada; sin embargo, esta puede verse modificada con el paso de los años por ser un producto transcultural:

14 Henríquez Puentes (2007) 105. 
Los trajes que se utilizan actualmente han provocado polémicas entre algunos folkloristas ya que son de terciopelo, de géneros de colores y llevan flecos dorados en las orillas a la usanza de otras danzas cuyos trajes son confeccionados en morerías y reflejan las modas españolas de los siglos coloniales ${ }^{15}$

La ideologización está relacionada con el depositario del espectáculo, que si bien pretende mantener la memoria de sus ancestros, al igual que con los trajes, el asunto ideológico puede modificarse según las necesidades del director de la puesta en escena.

La proxémica y la kinésica son factores muy cambiantes; están condicionados por el trabajo actoral. Aunque se haga una descripción detallada de la relación de un personaje con los otros y de cada actitud del personaje, el intérprete crea su propia forma de actuar desde su percepción del mundo e ideología. Los desplazamientos, como componentes del texto espectacular, pueden ser descritos por sistemas de notación coreográficos específicos, como el de Rudolf Laban ${ }^{16}$. Sin embargo, los sistemas no ponen de manifiesto la música ni el tempo de esta, por lo que el sistema es impreciso y se vuelve extremadamente complejo traducir el movimiento al alfabeto.

Quizás la música sea la que puede ser trasvasada de una manera más fiel, mediante la escritura en pentagrama, pero esto no quiere decir que posea el mismo valor, puesto que los instrumentos que musicalizan al Rabinal Achí son autóctonos y para la correcta transcripción, es necesario conocerlos. La plástica escénica ha ido modificándose con los años y aunque se hagan dibujos de los vestuarios, existe un grado de invención y creación por parte del depositario y su equipo, que hace que el espectáculo esté en constante evolución.

Las acciones son uno de los eslabones del texto espectacular más complejos, puesto que se les tiende a reducir al acto de habla y

15 Carlos García, Atlas danzario de Guatemala (Guatemala: Litografías Modernas, 1996) 152.

16 Rudolf Laban fue un coreógrafo húngaro que desarrolló un sistema notacional de escritura de la danza, que mediante un cifrado ubica la textura del movimiento, la dirección, la parte del cuerpo y la trayectoria. Ver Rudolf Laban, Danza educativa moderna (Barcelona: Paidós, 1975). 
por ende, a la palabra. La acción tiene la posibilidad de ser verbal y no verbal, está en directa relación con la kinésis y la proxémica (paralenguaje). El transvasamiento de la acción al texto implica una reducción, y aunque se utilice de manera minuciosa, las didascalias, lo que se escriba es solo la percepción del sujeto que observa y no la acción como tal.

Y en cuanto al texto espectacular, no se produce como un gesto caprichoso; representa el contexto cultural en el cual se desarrolla, pues utiliza los referentes teatrales que conoce y los extrateatrales que lo articulan.

Ya hemos argumentado sobre los diferentes componentes que conforman el acontecimiento teatral con el fin de poner en evidencia la magnitud de elementos que se dejan de lado al realizar la traducción, reducción o heteróclisis del espectáculo del Rabinal Achí al texto dramático. En los siguientes párrafos intentaremos argumentar el proceso al cual fue sometido el espectáculo en cuestión. El traslado de la oralidad indígena al texto escrito manifiesta, según Merleau-Ponty ${ }^{17}$, un proceso de recognición, reinterpretación y reconstrucción, es decir, el objeto inicial no es igual al objeto final, pues posee un filtro social, cultural y epistémico, que atraviesa al transvasador que convierte a $\mathrm{A}$ en B. Este proceso genera un producto heterogéneo, pues posee relación con el objeto inicial que representa a un contexto indígena (CI) pero también representa al contexto cultural del sujeto transvasador (CST), por lo que B contiene elementos de CI y de CST, pero no es fiel a ninguno de los dos, por lo que $\mathrm{B}$ es un objeto heterogéneo y representa un mestizaje cultural que no posee un porcentaje igual del primero ni del segundo, sino que se debe entender como heterogéneo.

A tal proceso denominamos heteróclito, pues se refiere a un objeto heterogéneo, compuesto de partes muy distintas entre sí, que generan un objeto irregular. Es la característica fundamental de los diferentes textos dramáticos que se han abstraído del espectáculo de Rabinal

17 Maurice Merleau-Ponty, Maurice, A estructura do comportamento. Trad. Márcia Valeria Martinez de Aguiar (Sao Paulo: Martins Fontes, 2006). 
Achí. El primero en generarlo fue el abate Brasseur Bourbourg, quien realizó una traducción al francés de un texto en quiché ${ }^{18}$, publicado en París en 1862. Georges Raynaud desarrolló otra traducción al francés desde el quiché en 1928. Luis Cardoza y Aragón efectuó a partir del texto de Raynaud una traducción al español en 1930.

¿Cuáles son esos componentes que hacen heteróclito el proceso de transvasamiento? El transvase de la tradición oral a la escritura articula subalternidad, diglosia y reducción. Estos tres fundamentos sesgan la riqueza del acontecimiento teatral para someterlo a un simple texto escrito, cuya función recae en preservar los enunciados verbales que se dicen en el texto espectacular por medio del alfabeto. Nos encargaremos de abordar la diglosia y reducción como metodologías para el transvase, y más adelante, analizaremos la subalternidad como ideología que sustenta este proceso.

La diglosia ${ }^{19}$ se entiende en su sentido amplio, no circunscrito a la lingüística. Es la convivencia de dos tradiciones teatrales en una misma población, donde $\mathrm{A}$ tendrá más prestigio que $\mathrm{B}$, porque A pertenece a una élite, y B relegado a costumbres inferiores, a la oralidad y al folklore. Sobre el concepto de reducción, es disminuir la importancia de un objeto hasta simplificarlo. Ambos conceptos se abordarán como binomio dentro del proceso heteróclito.

Brasseur Bourbourg, a pesar de haber visto la representación del espectáculo de Rabinal Achí en 1855, no incorporó didascalias en el texto dramático, omitiendo la relación que tienen el movimiento, la música y la plástica escénica con los diálogos. Esto acentúa el contexto cultural europeo desde el cual el abate produjo su traducción, ya que en el siglo XIX existía, en los movimientos teatrales de

18 Para Ruud van Akkeren en «El baile-drama Rab'inal Achí: sus custodios y linajes de poder», Brasseur Boubourg pudo haber tomado un texto escrito de Bartolo Ziz en lengua quiché del argumento del Rabinal Achí para realizar su traducción al francés.

19 Charles Ferguson acuñó el término en 1959: «La diglosia es una situación social en la que una comunidad de habla utiliza dos variedades de una lengua (diglosia en sentido estricto) o dos lenguas distintas (diglosia en sentido amplio) en ámbitos y para funciones sociales diferentes»; ver Paul Garvin y Yolanda Lastra, Antología de estudios etnolingüisticos y sociolingüísticos (México: UNAM, 1974) 247. 
Europa, un textocentrismo que es herencia de los siglos anteriores desde Aristóteles; por lo que es evidente el escaso valor que le dio el abate a los elementos espectaculares de Rabinal Achi; reduce el texto espectacular a un texto dramático.

El transvase de Bourbourg es producto de su visión europea, en la que cabe incorporar los estudios de Charles Ferguson, quien este propone nueve aspectos en los que se mueve el proceso de diglosia, y que para efectos de este escrito, se tomarán únicamente seis, que atañen directamente al proceso de transvasmiento que realizó el abate: (1) función, (2) prestigio, (3) herencia literaria, (4) adquisición, (5) estandarización y (6) gramática.

\section{Función}

Se refiere a la función especializada en la que se inscribe una forma teatral; es decir, las situaciones en las cuales tiene más valor un tipo de expresión teatral que otro. Las representaciones de tradición oral solo caben dentro del pueblo de Rabinal, pues forman parte de su cultura; en el momento en el que Brasseur decide hacer una traducción al francés necesita trasladarla a un formato especializado que sea entendible dentro de la cultura francesa y que quepa dentro de los parámetros académicos europeos.

\section{Prestigio}

Había dos maneras como se manifestó el teatro en Guatemala en el siglo XIX: las pastorelas, género dramático traído por la Colonia, similar en cuanto a forma y contenido a los autos sacramentales, cuya estructura proviene del Artenuevo de hacer comedias en este tiempo, de Lope de Vega. Data de principios del siglo XviI y tenía el propósito de evangelizar. Por otro lado, existía la danza-drama indígena, que desde su concepción incorporaban la música, la narración, el movimiento y la plástica. La traducción de Bourbourg debía inscribirse dentro del formato con más prestigio; por ello, adoptó las pastorelas, que consideraba superiores a las expresiones teatrales indígenas, como modelo. 


\section{Herencia literaria}

La herencia literaria es uno de los aspectos más complejos desde los cuales se trata el proceso de transvase, al menos, por tres aspectos: (i) se niega el conocimiento indígena como parte de una tradición oral milenaria; (ii) se omite el aniquilamiento de las bibliotecas mayas y los códices $^{20}$; y (iii) se concibe como herencia literaria solo lo producido en Europa. A partir de estos preceptos se reduce el Rabinal Achí a un texto dramático en el que se omiten los indicios escénicos del texto espectacular por mantenerse fiel a la palabra, que supuestamente, da soporte al argumento.

\section{Adquisición}

Se ha mencionado la presunta inferioridad que, desde la perspectiva europea, tenía la forma de hacer teatro del pueblo de Rabinal. Según Ferguson, para que exista una buena adquisición del lenguaje superior A, el B debe adoptar las características del primero y dejar de lado las formas supuestamente inferiores para que adquieran un mejor estatus. Esto es comprender que, desde la forma de hacer teatro europeo, se deba concebir la danza-drama indígena, violentando como tal a la cultura maya.

\section{Estandarización}

El aspecto homogeneizador es una de las constantes en el pensamiento europeo, durante la Colonia. Se entiende la estandarización como la conversión de lo otro a lo europeo para que se alcance una normalidad. En consecuencia, el transvase de la tradición oral a la escrita incorpora el conocimiento indígena dentro de los cánones europeos, es decir, en el formato de escritura de los textos dramáticos.

20 «La conquista española y lo que a ella siguió, alteró profundamente la cultura indígena y trastocó de modo particular sus formas de saber tradicional y los medios de preservación de sus conocimientos religiosos, históricos y de otras índoles. Sin exageración puede afirmarse que acarreó la fractura y a la postre la muerte de un sistema de preservación de conocimientos con raíces milenarias» (León-Portilla, 1996: 13). 
El hecho de generar la traducción posibilita que el Rabinal Achí forme parte del legado teatral «universal».

\section{Gramática}

El aspecto gramatical es de los más claros en el proceso heteróclito, pues se manifiesta al leer el texto en quiché, francés, español o inglés. Uno de los aportes de Taube ${ }^{21}$ sobre el Rabinal Achí, tiene que ver con la afirmación de que la traducción de Brasseur está sesgada por una visión del teatro europeo, y que omite la sintaxis y los recursos estilísticos que se hacen presentes en el texto:

In his 1862 publication, Brasseur presented the Rabinal Achi as prose, sectioned European-style into distinct paragraphs. However, with his recording of the performances and interviews with Jose Leon Coloch, Tedlock realized that the Rabinal Achi is in poetic verse, with extensive use of couplets and triads (Taube, 2007: 432) 22. $^{2}$.

El trasvasamiento del espectáculo al texto no solo resta valor al espectáculo al reducírsele a un texto dramático; también el texto pierde la riqueza de la sintaxis quiché. Ahora bien, conviene tener en mente el papel que desempeñó Bartolo Ziz en el proceso, pues efectuó la transcripción de lo oral a lo escrito en lengua quiché. Las razones no las podemos obtener de primera mano, pero algunos datos ayudan a dilucidarlas:

Rabinal Achí fue puesto en escritura alfabética, durante el siglo XIX, por una figura colonial europea, vinculada a la institución iglesia católica, específicamente por el cura párroco del pueblo de San Pablo de Rabinal, Brasseur de Bourbourg (Henríquez, Teatro maya 80, esc. 78). Éste, apoyado por Bartolo Zis, actor, director y dueño de la obra

21 Karl Taube, arqueólogo, etno-historiador y epigrafista estadounidense.

22 «En su publicación de 1862, Brasseur presentó el Rabinal Achí como prosa, seccionando al estilo europeo en párrafos distintos. Sin embargo, con su grabación de las actuaciones y entrevistas con José León Coloch, Tedlock se dio cuenta de que el Rabinal Achí está en verso poético, con el uso extensivo de coplas y tríadas» (traducción propia). 
hasta 1825, y por Vicente Tecú, ayudante de capilla (Sacor 13), lo transcribió al quiche y luego al francés, desencadenando con esto un proceso de construcción de sentido que fijó en escritura aquello que había sido conservado por tradición oral, es decir, trasladó un texto desde una de sus actualizaciones efímeras a "una versión definitiva", concepto ajeno a las culturas orales (Lienhard 10) y por sobre todo, a la naturaleza del arte teatral ${ }^{23}$.

Por ser indígena Bartolo Ziz, depositario del Rabinal Achí y descendiente directo de los jerarcas de los rabinales ${ }^{24}$, encuentra en el transvase una forma de resguardar la memoria del pueblo de Rabinal, y exponer hasta adónde fueran posibles los acontecimientos de sus ancestros, y al mismo tiempo, de mostrar que existe un conocimiento indígena no europeo con una tradición milenaria que fue saqueada por la colonia. Mientras que Brasseur Bourborg, abate europeo, consciente de la importancia del Rabinal Achí para el pueblo de San Pablo de Baja Verapaz, lo reduce a un texto dramático. Se inscribe dentro del legado europeo para darle validez; con esto lo exotiza ante la élite académica europea. El proceso es complejo, por lo que en el siguiente apartado vamos a analizarlo desde la perspectiva descolonial, con el fin de poner en contexto la relación de subalternidad que engloba y caracteriza la heteroclisis.

\section{Rabinal Achí: subalternidad, transculturación y heterogeneidad}

Partamos de explicitar los postulados con los que se analiza el proceso de escritura, a partir de las nociones de subalternidad, transculturación y heterogeneidad. Se hace una separación terminológica con fines expositivos, pero su interrelación permite transitar de una a otra por tratarse de un proceso cultural. Los resultados que puede arrojar este análisis son extensos, por lo que nos centraremos en algunas

23 Henríquez (2010) 226.

24 Raud Akkeren, «El baile-drama Rab'inal Achí: sus custodios y linajes de poder» Mesoamérica 40 (2000): 1-39. 
ideas principales, y que a nuestro juicio, hacen un somero recuento de las implicaciones de estos conceptos en el proceso escritural.

Brasseur Bourbourg traduce al francés los diálogos dictados (o escritos) por Bartolo Ziz en 1856, para su publicación en 1862. Esto permite interpretarlos desde varias perspectivas: la primera, entender que existe un acto de «buena fe» por parte del abate Bourbourg, el cual pretende, a partir de su traducción, perpetuar el legado cultural del pueblo de Rabinal; la segunda radica en plantear que Bourbourg consideró que la única forma de darle validez al espectáculo consistía en envasarlo dentro de una forma de producción literaria, específicamente, la teatral europea; la tercera, exponer dentro de la estructura literaria europea un legado exótico, en el que ofrece un panorama general del espectáculo a partir de los textos de los personajes, generando así un proceso inverso al de la producción dramática, es decir, no se escribe para que luego se represente lo que se ha escrito, más bien se escribe lo representado violentando la esencia misma del espectáculo.

Desde una perspectiva heterogénea, cabe señalar la actitud de Bartolo Ziz, y preguntarnos sobre los casos que condujeron a transvasar el espectáculo a un texto dramático. Tales casos podrían sintetizarse en la necesidad de resistencia del pueblo quiché por negarse a una pérdida de la memoria de su cultura como ocurrió siglos antes con los códices, o porque existe una colonización del pensamiento en el que se considera que el texto escrito tiene mayor validez.

Son cinco posibles casos admisibles, pues responden a un contexto social, político, económico y cultural que brinda la plataforma ideal para que este proceso heteróclito se lleve a cabo. Vale la pena detenernos en aspectos sobre el contexto del siglo XIx en Guatemala, pues estos datos permitirán visualizar algunas necesidades ideológicas y políticas que brindaron el terreno perfecto para que Bourbourg generara la traducción al francés.

En los primeros decenios del siglo XIX cobró su independencia la Capitanía General de Guatemala de la Corona Española. A partir de esta separación, surgen movimientos liberales y unionistas en las 
diferentes provincias de Centroamérica, que provocan conflictos sociales para determinar lo que cada grupo consideraba mejor, así se mantuvo hasta la conformación de los estados y a su vez, del proyecto político que determinaría la identidad de la nación.

Edelberto Torres ${ }^{25}$ ofrece un buen panorama sobre la idea de nación y sus problemas teóricos e históricos, en el cual señala que han existido varias nociones de lo nacional, primero como algo natural y correspondiente a una etnia, y luego como un proyecto ideológico en el que se busca homogenizar a una población que está ubicada en determinado territorio. La idea de nación está sustentada en prácticas económicas, políticas, sociales y culturales que brindan una determinada nacionalidad, que para entrar en ella se debe adoptar todos esos rasgos como elementos identitarios.

El constructo nación es establecido por una élite política y económica que se hace valer de las estructuras de enseñanza, adoctrinamiento y de las esferas sociales para delimitar las funciones de cada individuo dentro del Estado. Además, debe seguir y defender las ideologías hegemónicas para que sea considerado parte de la sociedad. ¿Pero qué pasa con los pueblos que no entran dentro de los estándares homogéneos de la sociedad dictada por la nación? Es acá donde ocurre una diglosia social, pues para ser considerado parte de lo nacional debe adaptarse a los modelos establecidos por las clases dominantes. Este mismo proceso sucede con las diferentes culturas que se manifiestan en un determinado territorio, a pesar de convivir en un mismo espacio geográfico, no todas tienen la misma validez desde la óptica hegemónica.

Rabinal Achí no se sustrae de esta concepción ideológica. La relación entre lo indígena y lo criollo presupone un sistema de subalternidad en el que lo primero está en una posición de desventaja o inferioridad respecto de lo segundo, encargado de establecer los parámetros de lo que es cultura, por tener una posición superior o de

25 Ver Julián González, «Los valores culturales americanos en el Rabinal Achi», Repertorio Americano 2 (enero-marzo, 1982): 14-18. 
privilegio. Desde esta perspectiva, volvemos a traer el tema de que el Rabinal Achí, como acontecimiento teatral que forma parte de una tradición oral ancestral, y en consecuencia, se encuentra en una posición inferior respecto a las formas de los productos culturales de las clases dominantes; ya que estas poseen un sesgo europeo y colonizador.

Al considerar la propuesta de Lienhard ${ }^{26}$ sobre las literaturas alternativas, Rabinal Achi forma parte de este grupo, pues se encuentra al margen de las escrituras occidentales por ser la comunicación oral, que predomina sobre la escritura textual. Estas literaturas alternativas, desde la perspectiva de la subalternidad, llegan a ser válidas si se inscriben dentro de las estructuras de la literatura occidental. Pero esto no es garantía, pues a pesar de incorporar la tradición oral al género escrito, no se alcanza una relación de igualdad respecto a los otros productos literarios que fueron concebidos dentro del género escrito, ya que poseen una conciencia y voz indígena subyacentes.

El fenómeno que propone Lienhard demuestra la contraposición de dos culturas, de dos pueblos distintos: el europeo y el indígena. El europeo se relaciona con el centro y el indígena con la periferia. El centro determina los «procesos adecuados», que generalmente obligan a las periferias a renunciar a su visión de mundo, sus tradiciones y costumbres para que se acerquen al centro. Un ejemplo de ellos fue la colonización y evangelización.

Pero este criterio no es tan llano, el encuentro cultural no sucede en una única dirección. A partir de esta percepción, vale traer la definición de transculturación de Malinowski:

Transculturación es un proceso en el cual emerge una nueva realidad, compuesta y compleja; una realidad que no es aglomeración mecánica de caracteres, ni siquiera un mosaico, sino un fenómeno nuevo, original e independiente. Para describir tal proceso, el vocablo de raíces latinas transculturación proporciona un término que no contiene la implicación de una cierta cultura hacia la cual tiene que

26 Norbert Lechner (comp.), Estado y política en América Latina (México: Siglo Veintiuno, 1981) 87-132. 
tender la otra, sino una transición entre dos culturas, ambas activas, ambas contribuyentes con sendos aportes, y ambas cooperantes al advenimiento de una nueva realidad de civilización ${ }^{27}$.

La transculturación no es homogénea; por el contrario, es heterogénea en cuanto reconoce que la suma de dos culturas no es igual a una tercera, pues la cultura no se descompone y se une con otra para obtener homogéneamente a la tercera, existe la posibilidad de que parte de la primera cultura pueda mantenerse intacta, o asumir algunos repertorios de la segunda, o en que haya un entretejido más diverso en el que se unan aspectos de una con los de la otra; pero incluso en estos, la zona geográfica, el lenguaje y la alimentación serán factores que harán heterogénea una nueva cultura.

Esta definición es clave para entender la relación que existe entre Bartolo Ziz y Brasseur Bourbourg. Ambas posiciones culturales poseen son codependendientes. Para explicarlo mejor, se tomará de referencia el sujeto enunciador, el discurso y la representación como producto final:

\section{Sujeto enunciador}

En este proceso de transculturación hay dos sujetos culturales que generan enunciados. El primero es Bartolo Ziz, que tal y como lo hemos mencionado anteriormente, sabía escribir y era el depositario del Rabinal Achí. Por lo que el acto de brindar por escrito o mediante un dictado los textos que se dicen en el espectáculo encierra una acción de facilitar el conocimiento, de poner en evidencia una memoria ancestral. Por otro lado, se encuentra Bourbourg, un sacerdote católico de origen francés que escribe un texto dramático con el contenido facilitado por Ziz y que lo traduce e inscribe según su conocimiento, dentro los parámetros del ámbito académico.

27 Bronislaw Malinowski, Contrapunto cubano del tabaco y el azúcar (La Habana: Editorial de Ciencias Sociales, 1983) XIII. 


\section{Discurso}

En el caso de Bartolo Ziz, a partir de la facilitación del contenido que le da al abate Bourbourg, queda manifiesta su perspectiva de preservar en la memoria indígena y europea las tradiciones del pueblo quiché. En sus actos aflora un acto de resistencia para que su pueblo no sea olvidado, inlcluso es parte de una denuncia pasiva de aquel aniquilamiento del pueblo maya y sus conocimientos en la primera etapa de la conquista española. Para el clérigo, además de mostrar un producto indígena, se pueden abstraer algunos rasgos de exotización de lo indígena. Esto se demuestra al tener en cuenta el lugar de la publicación y el idioma al que se traduce, pues no se dirige al pueblo guatemalteco sino a la élite académica francesa.

\section{Representación}

En el caso de Bartolo Ziz, la transcripción del texto no fue el condensador del acontecimiento teatral, solo fue un soporte memorizador; Rabinal Achí, como fenómeno cultural, siguió funcionando como un baile-drama con todas las implicaciones del texto espectacular. En el caso Brasseur, existe una reducción del producto cultural original en un texto dramático que sirve para exponer el poco alcance que tiene un texto dramático respecto a la tradición oral. La estructura occidental es muy cerrada para la magnitud que representa un acontecimiento teatral. Pero este resultado no se desacredita, pues en términos de transculturación es un producto heterogéneo en el que no es fiel a una cultura ni a la otra, simplemente es un producto heteróclito.

Cabe relacionar la institución que representa Bourbourg con el Estado, pues la Iglesia forma parte importante del aparataje que ayudará a identificar al ciudadano en el concepto de nación, pues deberá ser católico y seguir los lineamientos sociales y políticos de la cúpula. Tras la independencia en 1821, es significativo buscar rasgos autóctonos que identifiquen a las provincias, de ahí se dirige la mirada hacia lo indígena como un ente que podría, desde cierta óptica, funcionar para tales fines. A partir de este proyecto, Rabinal 
Achí es un factor útil, porque tiene un recorrido histórico ancestral y precolombino que podría emplearse como estandarte de identidad, pero esta identidad es exótica y de accesorio, pues solo funciona como un símbolo para distinguirse y no como un proyecto de construir una nación en conjunto entre los indígenas y la élite política.

\section{Consideraciones finales}

Durante el siglo XIX predominó una tendencia en Latinoamérica a incorporar toda la producción literaria prehispánica o colonial a los estándares europeos. Esta circunstancia arroja una luz desde la cual se percibe la traducción del Rabinal Achí por parte de Brasseur Bourbourg, pues esta surge de un ejercicio por dar validez al texto espectacular, y reducirlo a un formato de características europeas, que no tiene relación con el referente original. En el siglo xx, en varias latitudes del continente americano, surgió una serie de movimientos políticos que procuraban despertar de nuevo la conciencia nacional y volver la mirada al indio y su lugar en la sociedad:

En general los contextos políticos en América Latina favorecieron distintos modos de opresión, marginación y exclusión hacia los pueblos indígenas que permitieron la apropiación de sus tierras ancestrales, la extracción de sus recursos naturales y la degradación del medio ambiente. La implementación de políticas inadecuadas para las sociedades nativas comporta un intenso proceso de empobrecimiento de las mismas que torna indispensable y urgente revertir esta situación ${ }^{28}$.

A principios del siglo $\mathrm{xx}$, este movimiento se hace presente en la literatura regional, en la que se desarrolla una producción con temas indígenas, que algunos estudiosos denominan indigenista, mientras que otros, indianista. La división será determinada por el sujeto enunciador y el discurso de la ficción; tanto el indianismo

28 Javier Rodríguez, «Los movimientos indígenas en América Latina. Resistencias y alteridades en un mundo globalizado», Gazeta de antropología 24 (2008). 
como el indigenismo son producidos por sujetos ajenos a la población indígena; la diferencia consiste en que el indianismo aborda temas supuestamente indígenas pero que no tienen relación alguna con la cultura representada, pues solamente son ficción y una idealización. Por otro lado, el indigenismo también genera una ficción, pero se preocupa por hacer una crítica sobre los problemas sociales, políticos y económicos que experimentan los indígenas.

¿Qué relación hay entre estos movimientos y el Rabinal Achí? Aunque se producen medio siglo después de la traducción que hace Brasseur Bourbourg, expone una problemática indígena, el olvido de una cultura. El acto de resistencia de Bartolo Ziz al facilitar el conocimiento del producto cultural del pueblo de Rabinal forma parte de un movimiento indigenista. Al considerar al sujeto enunciador, este es indígena, Bartolo Ziz, ya que Brasseur Bourbourg solo es el depositario para ejecutar la traducción. Es mejor situar el transvase en una literatura indígena producida por indígenas, para indígenas y culturas no indígenas. El acto de resistencia de Bartolo Ziz es un gesto vital, pues utilizó las intenciones de una élite para preservar un legado cultural. Asimismo, empleó sus propia voz para enunciar un legado y evidenciar un olvido. El producto final es heteróclito, pero transculturalmente valioso pues genera una memoria que espera ser sostenida y proyectada por varios siglos.

\section{Conclusiones}

El proceso heteróclito de Rabinal Achí es resultado de una diglosia, en la que el espectáculo no se dimensiona cabalmente, aunque genera un nuevo producto heterogéneo que responde a un proceso transcultural. La institución representada por el abate es parte de los procedimientos colonizadores de pensamiento, pues negó la institucionalidad indígena y provocó una relación de subalternidad. La traducción de Bourbourg responde a un contexto que buscaba establecer 
elementos identificadores de la nación a partir de la exotización de la cultura autóctona.

Rabinal Achí constituye un punto de referencia para comprender la literatura indígena, antes del movimiento indianista o indigenista, pues algunos estudiosos lo pasan por alto y establecen el período indigenista a finales del siglo XIX y principios del siglo XX, dado que en realidad el proceso por establecer una voz indígena se establece medio siglo antes, en el momento en que Bartolo Ziz, como parte de un acto de resistencia, facilitó su conocimiento para mostrar que su cultura había sido olvidada y suplantada. 
